This is an Accepted Manuscript of an article published in Hispanic Research Journal, 17:4. Published online: 18 Aug 2016, DOI: https://doi.org/10.1080/14682737.2016.1200854

To cite this article: Raquel Merino Álvarez (2016) Censura, traducción e integración en el teatro de la época franquista: José López Rubio, hombre de teatro y traductor, Hispanic Research Journal, 17:4, 303-321, DOI: 10.1080/14682737.2016.1200854

\title{
Censura, traducción e integración en el teatro de la época franquista: José López Rubio, hombre de teatro y traductor
}

\author{
Raquel Merino Álvarez ${ }^{1}$
}

\section{Introducción}

La historia del teatro español del siglo veinte, desde el final de la guerra civil (1939) hasta, al menos, finales de la década de los setenta se vio marcada por la vigencia de un régimen autoritario que estableció un sistema de control sobre todo tipo de manifestación cultural. La censura franquista, en lo relativo a la cultura y por tanto en todo lo relacionado con manifestaciones dramáticas como el teatro, se materializó como estructura burocrática que obligaba a filtrar y depurar las obras destinadas a todo tipo de público. Este filtro, previo a la autorización, se aplicó de un modo metódico, dejando en consecuencia abundantes rastros de lo que fue el devenir cultural de buena parte del siglo pasado.

Para los estudiosos del teatro español los archivos de censura custodiados en el Archivo General de la Administración (AGA) son una fuente inagotable de documentación e información de muy diverso tipo, y para aquellos que nos planteamos estudiar el componente aportado por la traducción en la historia del teatro español, dicho archivo es, además, un yacimiento documental único. En él podemos rastrear el acontecer teatral de nuestro país, sin límites respecto a la lengua o país de origen de los autores cuyas obras fueron representadas y publicadas, o al menos seleccionadas para su representación o publicación. La preceptiva solicitud de autorización para hacer público un hecho teatral abría todo un proceso burocrático-censor que quedó minuciosamente registrado y reflejado en cientos de documentos. Esos registros son, en muchos casos, la única fuente con la que podemos contar para reproducir las vicisitudes de la obra dramática traducida de nuestra historia teatral.

Aunque pueda parecer superfluo, conviene apuntar que las diferentes historias del teatro español, tanto las publicadas a lo largo del

\footnotetext{
1 Universidad del País Vasco, UPV/EHU. Grupo de Investigación Consolidado GIC12/197, Gobierno Vasco IT728/13. Proyecto FFI2012-39012-C04-01T, Ministerio de Economía y Competitividad.
} 
siglo veinte (García Lorenzo, 1981; Díez Borque, 1982 y 1988; Ferreras, 1988; Ruiz Ramón, 1989; Berenguer \& Pérez, 1998; Bonnin ,1998) como las más recientes (Miguel Martínez, 2000; Oliva, 2002; Huerta Calvo, 2003), no suelen reflejar la existencia de traducciones en el teatro representado y publicado en España. La razón es tan simple como evidente: el enfoque que tradicionalmente se adopta consiste en recabar información sobre dramaturgos españoles, obras en español (catalán, gallego o vasco), o teatros o compañías españolas, entendiendo como tales los originados geográfica o lingüísticamente en el territorio español. Todo aquello que tenga que ver con autores extranjeros se suele excluir, e incluso las traducciones realizadas por los dramaturgos españoles suelen obviarse o considerarse ajenas cuando no de menor categoría (Merino, 2010: 374).

Creemos conveniente insistir en que el teatro traducido es teatro español, y en español (catalán, gallego o vasco). Una vez traducidas, las obras de los dramaturgos extranjeros entraron a formar parte, en la época que nos ocupa, del repertorio de todo tipo de compañías haciendo posible la innovación y la introducción de temas específicamente controlados por el aparato censor.

Por ello, desde una perspectiva traductológica, nuestro objeto de estudio no es otro que la traducción y las traducciones, como hechos de la cultura que las origina, produce y aloja; en nuestro caso, la cultura teatral española, en la que se integran tanto el teatro en versión original como el traducido. Y es que "vivimos inmersos, querámoslo o no, en una cultura cuyo rasgo más característico, más señalado y decisivo es el de ser una cultura traducida" (Santoyo Mediavilla, 1983: 41). A pesar de esta realidad, el teatro en traducción ha quedado reducido, hasta ahora, a la documentación preservada en las páginas de los archivos de censura, algunas ya conocidas, estudiadas y difundidas, la mayoría olvidadas y excluidas de estudios fundamentales para la reconstrucción de una historia integral del teatro español.

\section{El teatro extranjero traducido y la censura franquista: más allá de un teatro en versión original}

Nuestro propósito al recurrir a los archivos de censura no ha sido otro que recopilar datos sobre autores y obras extranjeros que nos ayuden a reconstruir una parte de la historia teatral española de cuyo ámbito, como acabamos de decir, se han visto marginados. El poso que el teatro extranjero fue dejando en la cultura española se suele rastrear o bien a partir de las obras publicadas, tanto en ediciones de lectura como en ediciones escénicas (Merino, 1994; Pérez López de Heredia, 2005; Puebla, 2012), o bien recurriendo a las críticas recogidas en la prensa diaria y especializada (Pérez, 1998; Muñoz Cáliz, 2012). Incluso recopilaciones de críticas teatrales como la publicada por Francisco Álvaro desde 1958 a 1985 han servido tradicionalmente como fuentes de 
datos respecto al teatro extranjero representado en España.

Pero obviamente los archivos de censura aportan una nueva dimensión, un punto de vista diferente, pues nos permiten observar el teatro, traducido en nuestro caso, antes incluso de su producción y difusión. Los textos se nos presentan en su primer contexto de recepción: la lectura y evaluación de los manuscritos por parte de los censores encargados de informar la solicitud de representación o publicación. En este estadio previo quedaron, por tanto y necesariamente, archivadas todas las páginas que, una vez modificadas, llegarían a los escenarios o, en algunos casos, permanecerían allí olvidadas. La acumulación de datos cuantitativos y cualitativos, procedentes de dichos fondos, nos permite reconstruir la historia del teatro extranjero que llegó al público español. Pero no sólo eso; también la de aquellos textos traducidos que no llegaron a representarse o publicarse, pero para los que se solicitó autorización $y$, por tanto, quedaron registrados en este yacimiento documental indispensable que es el AGA (Merino, 2010: 363).

Esas primeras versiones, manuscritos mecanografiados en su mayoría, junto con la documentación generada en torno a ellas y conservada en el archivo, sirven para reconstruir el proceso de integración del teatro extranjero en nuestra cultura. Así como en cualquier otro contexto es muy difícil acceder a textos intermedios de una misma obra, en el caso de los archivos de censura ésa es precisamente la naturaleza de lo guardado. Los documentos que se generaron a partir de cada solicitud de representación, o publicación, archivados bajo un número de expediente, nos ofrece un carácter casi gráfico, son una suerte de "instantáneas" o "fotogramas" que, puestos en secuencia, permiten reproducir un rudimentario metraje documental que ayuda a entender qué obras teatrales extranjeras llegaron a representarse, de qué modo se produjo su autorización y quiénes fueron los protagonistas de dicho proceso. Partiendo de este tipo de evidencia podemos reconstruir también la historia del teatro que no llegó a existir en un espacio escénico público y podemos, incluso, deducir las razones que impidieron que ciertas obras llegaran a representarse.

La metodología que hemos utilizado para reconstruir la historia del teatro traducido se basa en la recopilación de traducciones, un procedimiento que comienza con consultas aleatorias en los archivos de censura, y la catalogación de cada traducción que se identifica al abrir cajas AGA. La cuantificación del material encontrado, y el análisis de los registros, que contienen datos como título, autor, nacionalidad o traductor, permite identificar casos representativos, basándonos en la recurrencia de dichos datos. El análisis cualitativo de los mismos nos lleva a realizar búsquedas guiadas (onomásticas o por título) que permiten llegar a estudios de casos prototípicos (Merino Álvarez, 2010: 365). Es difícil establecer dónde comienza y dónde termina el componente cuantitativo y el cualitativo en nuestro método de trabajo; se trata más 
bien de un procedimiento en espiral (Toury, 2004: 79): el hallazgo de un fenómeno o caso concreto nos lleva a profundizar en la búsqueda de datos sobre el mismo; pero al tiempo suele generar nuevas búsquedas que permiten abundar en la cuantificación de traducciones ampliando los catálogos existentes.

Una relación de los autores extranjeros registrados con mayor frecuencia, en particular los anglosajones, comienza con clásicos como Shakespeare, continúa con dramaturgos como Beckett, O’Neill, Shaw, Williams, Greene, Shaffer o Rattigan y se completa con una serie de autores comerciales de fama efímera (Merino Álvarez, 2012: 129). Así también la lista de nombres españoles, cuyos trabajos aparecen bajo etiquetas como traducción o versión, se extiende desde un extremo ocupado por dramaturgos que esporádicamente firmaban versiones (Pemán, Salom o Sastre), y continúa con escritores que, como José López Rubio, contribuyeron al teatro español tanto con producción propia como con abundante obra en traducción. Se amplía dicho abanico con nombres de actores y directores que fueron a su vez autores de obra original y traducida (José Luis Alonso o Adolfo Marsillach) y se añade a este espectro onomástico un colectivo de hombres y mujeres vinculados al teatro que firmaron únicamente versiones (González Vergel) actuando no tanto como "traductores" sino como vehículo de transmisión del teatro extranjero. Por último, localizamos un exiguo número de traductores profesionales (Carla Matteini o José Méndez Herrera) que es el menos visible de los colectivos involucrados en la "re-producción" de obras extranjeras (Merino Álvarez, 2012:136).

Datos como los anteriores, que manejamos y hemos tratado en otras publicaciones, proceden de búsquedas no predeterminadas y por tanto no excluyentes. La documentación obtenida en los archivos de censura nos ha llevado a analizar estudios de casos en torno a nombres de dramaturgos y títulos de obras extranjeras que, a priori, no habrían sido considerados representativos: Ejercicio para cinco dedos de Peter Shaffer (1958) El amante complaciente de Graham Greene (1967) o Los chicos de la banda de Mart Crowley (1975) son obras que, traducidas, consiguieron vencer el veto censor, se representaron y ayudaron a introducir en nuestra cultura temas delicados relacionados con la moral sexual, particularmente el adulterio (Merino Álvarez, 2012: 134) y la homosexualidad (Merino Álvarez, 2008).

\section{José López Rubio: producción escénica en versión original y traducida}

Desde la perspectiva de la historia del teatro español, López Rubio es una figura singular, cuya producción, aunque jalonada por hitos muy significativos, ha sido objeto de escasos estudios (Holt, 1964 y 1980; Rogers, 1980; García Ruiz, 2007a y 2007b; Rodríguez Fischer, 2008), centrados por lo 
general en su obra original. Entre la nómina de premios y reconocimientos que obtuvo cabe destacar el nombramiento como miembro de la Real Academia Española (1983). En su discurso de ingreso ('La otra generación del $27^{\prime}$ ) se pueden encontrar las claves del limitado reconocimiento que ha sufrido su obra y la de muchos de sus compañeros de generación (Romera Castillo, 2003; Torrijos, 2003).

Teniendo en cuenta esta presencia continuada y diversa en los medios dramáticos durante más de medio siglo (Retratos, 2006), llama poderosamente la atención que la obra de López Rubio no haya suscitado más interés entre los investigadores españoles o entre los hispanistas extranjeros. Estudios monográficos como el de Holt (1980), o aportaciones de menor extensión como las de García Ruiz (2008: 264-69), no hacen sino resaltar dicha carencia.

Este "verdadero mediador en la recepción española del teatro inglés y norteamericano" (García Ruiz, 2007b: 89), "hombre de teatro" (Holt 1980: 15) a caballo entre la producción propia y la traducida, se erige como el dramaturgo-traductor más importante de su generación (Holt, 1975: 29). El estudio de su dilatada producción dramática, que comienza en los años veinte del siglo pasado, nos permite recorrer la historia escénica española del periodo que va desde el final de la guerra civil (1939) hasta la aprobación de la Constitución (1978). El poso que su labor ha dejado en el teatro español se puede reconstruir y proyectar, a modo de metraje documental, poniendo en secuencia las instantáneas y recortes de aquellos acontecimientos teatrales en los que participó activamente y que han quedado reflejados en documentos archivados, publicados y grabados.

Aunque en la presente aportación hemos querido poner el foco de atención en la cultura teatral traducida, y por tanto en la labor de López Rubio como traductor, al proceder a catalogar en detalle su obra hemos optado por integrar tanto la original como las versiones que realizó de autores extranjeros (ver Anexo I). De este modo se podrá valorar la producción del traductor sin dejar de lado el legado del dramaturgo. Para ello hemos centrado nuestras búsquedas en la fuente que mayor riqueza documental nos ofrece, referida al siglo $\mathrm{XX}$, tanto en número de entradas como en variedad: los archivos de censura.

Partiendo de los resultados, 24 títulos originales y 18 traducciones a nombre de López Rubio, que se recogen en la base de datos de censura teatral del AGA (046 Sección Cultura), hemos cotejado y completado dichos resultados con información procedente de búsquedas directas en las cajas archivadoras, así como en las fichas manuales de autores de teatro correspondientes a dichos fondos de censura (Merino, 2011).

Una vez establecido un primer catálogo de textos escénicos, cuyas solicitudes de representación habían sido tramitadas ante las instancias 
censoras a nombre de José López Rubio, en calidad de autor o traductor, se procedió a cotejar y completar dicho catálogo con información de otras fuentes documentales. Así se han incorporado datos procedentes del Centro de Documentación de las Artes Escénicas de Andalucía (CDAEA), custodio del legado documental del propio autor y del Centro de Documentación Teatral (CDT). Del mismo modo la información que aportan estudiosos como Holt (1980), Isabel Estrada (2001: 216-217) Torrijos (2003) o García Ruiz (2008: 264-69) se ha integrado en la relación final de obras.

Una vez refundidos todos los datos referentes a textos teatrales firmados por José López Rubio con vistas a su puesta en escena, vemos que nuestra recopilación final recoge 69 títulos diferenciados: 44 se corresponden con traducciones, uno es adaptación, y 24 son obras originalmente escritas en español (Anexo I). Se trata de una catalogación exhaustiva que, comparada con las ya existentes, reúne, refunde y amplía los datos disponibles hasta la fecha.

La producción de López Rubio, así catalogada, se extiende a lo largo de cuarenta años y podría distribuirse en cuatro periodos diferenciados: desde los primeros estrenos teatrales hasta el final de la guerra civil (1929-1939); la vuelta a los escenarios españoles en la década de los cuarenta (1944-1954), un periodo en el que ya encontramos mayor número de traducciones que de obras originales; la consolidación como dramaturgo y traductor de teatro extranjero (1955-1965), con más del doble de traducciones respecto a producción propia; y un cuarto periodo que va desde la época de apertura hasta el final del franquismo (19661976), y que también se distingue por una mayor presencia de teatro traducido.

\subsection{Primeros estrenos teatrales y estancia en Hollywood:1929-1939}

López Rubio hace su aparición en la escena teatral española con dos obras escritas al alimón con Eduardo Ugarte, yerno de Arniches y cofundador de La Barraca: en 1929 se estrena De la noche a la mañana, que recibe el premio $A B C$, y un año después, en 1930, La casa de naipes. Ese mismo año es contratado, junto con un grupo nutrido de profesionales del teatro, incluido Ugarte, para trabajar en Hollywood, primero en la Metro y más tarde en la Fox. Su nuevo papel como integrante de esa "peculiar diáspora" (Romera Castillo, 1997: 8) de dramaturgos españoles se centra en la escritura de guiones para las denominadas versiones dobles (Armero 1995; Utrera Macías, 1987). En el año 1936, de vuelta en España, interviene en la adaptación cinematográfica de La Malquerida de Benavente, pero el rodaje se ve interrumpido por el alzamiento de julio y no se materializa hasta después de la guerra civil. José López Rubio continúa trabajando como guionista y adaptador en la industria del cine, tanto en Hollywood como en Méjico, hasta su regreso a España al finalizar la contienda (Holt 1980: 19-21). 


\subsection{Vuelta a los escenarios españoles como dramaturgo y traductor: 1944-1954}

En la década de 1940 López Rubio vuelve a los escenarios españoles, como un dramaturgo "semi-novel" (García Ruiz 2007a: 85) y se convierte en traductor destacado de autores norteamericanos y europeos (Holt 1975: 29). De los 69 títulos recogidos en el catálogo de textos escénicos firmados por López Rubio, a este decenio corresponden 28 entradas: 16 traducciones y 12 obras originales.

Todo parece indicar que la primera obra firmada por José López Rubio que obtiene permiso de representación en la época franquista es El pasado de la Sra. Cheyney, del estadounidense Frederick Lonsdale (1945). Le sigue la autorización y estreno, en 1947, de El tiempo dormido, traducción de la obra del británico Ben W. Levy (García Ruiz 2007b: 89). Se suceden en este periodo versiones de obras, como Belinda (1950), que llegan precedidas de un historial escénico y cinematográfico de éxitos y polémicas en Estados Unidos y que marcarán la tónica del tipo de teatro que José López Rubio traducirá en las siguientes décadas. Alberto, estrenada en 1949, supone su "reingreso en el mundo del teatro" (García Ruiz, 2007b: 89) y la primera obra original autorizada en este periodo. Dos años más tarde lo sería Celos del aire, que obtuvo el Premio Fastenrath en 1951.

En 1952 destacan títulos emblemáticos como La muerte de un viajante, de Arthur Miller o La importancia de Ilamarse Ernesto de Oscar Wilde. Se produce el estreno de la obra La esposa constante del británico Somerset Maugham, tras el éxito fulgurante cosechado por la producción americana en Broadway. Siete años antes, se había registrado la primera solicitud de representación de esta obra (1944); aunque no consta en los archivos del AGA que se autorizara la representación, por lo que suponemos que fue prohibida y archivada por presentar abiertamente el tema del adulterio.

\subsection{Consolidación como dramaturgo-traductor: 1955-1965}

En este decenio la producción traducida de José López Rubio duplica a la original: 21 traducciones, más una adaptación de un drama de Lope, frente a 9 títulos propios. Se trata de un periodo particularmente productivo en el que se suceden estrenos de títulos como los musicales EI caballero de Barajas, original de López Rubio y Al sur del Pacífico, importado de Broadway (1955); o la adaptación al teatro y al cine de la novela de Faulkner Requiem para una mujer (1957), todos ellos éxitos de taquilla. Predominan obras de autores estadounidenses, pero López Rubio suscribe también un grupo significativo de títulos de autores 
británicos y franceses. $^{2}$

Gracias a la labor de este profesional como traductor-mediador aparecen en la escena española temas y autores variados, y la consulta a los expedientes nos muestra que en todos los casos la censura oficial, o la autocensura previa, influyó en el texto final representado, cuando no en las propias representaciones. En algunas ocasiones, como ya se dijo, el texto traducido y presentado a censura nunca llegó a representarse y permanece aún hoy olvidado; tal es el caso de Panorama desde el puente de Arthur Miller (Merino Álvarez 1994: 172).

\subsection{Proyección exterior: 1966-1976}

En la segunda mitad de los años 1960, López Rubio viaja por EE.UU. dando conferencias en instituciones universitarias (Holt, 1980: 11-13). Allí se publican y representan las primeras traducciones al inglés de su obra. Esta actividad exterior no impide que continúe su presencia en los escenarios españoles. Entre 1966 y 1976, encontramos seis títulos del catálogo correspondientes a traducciones y cuatro a obras propias. Destacan los musicales, El hombre de la Mancha y Sonrisas y lágrimas, y las obras Adriano VII y Harold y Maude, todos ellos éxitos escénicos, que ya se habían adaptado a la gran pantalla en EE.UU. Entre la producción original llevada a escena en este periodo, cuatro obras, destacan La puerta del ángel, El corazón en la mano (premio Nacional de Teatro en 1972) y El último hilo (1974).

A partir de 1976 las entradas que encontramos corresponden a expedientes de reposiciones o solicitudes de "calificación" posteriores a la aprobación de la legislación sobre libertad de espectáculos teatrales y la Constitución (1978), cuando el control burocrático y las oficinas encargadas han sido re-denominadas de "ordenación" y "calificación". Las manos son inocentes (1980), Crimen Perfecto y La otra orilla (1981) y La muerte de un Viajante (1984) se clasifican para mayores de 14 años, generando sendos expedientes en los archivos custodiados en el AGA, en la sección Cultura ${ }^{3}$.

\subsection{José López Rubio en el ámbito editorial}

Si valoramos los datos recogidos en el catálogo, comparando piezas traducidas frente a producción propia, comprobamos que las obras de autores extranjeros versionadas por López Rubio, constituyen un 64\% frente al $36 \%$ de obra original. Esta imagen que nos ofrece la actividad escénica no se corresponde con la presencia que el nombre del

\footnotetext{
${ }^{2}$ El teatro inglés tenía ya entonces una tradición arraigada en el teatro español. El director del María Guerrero, Luis Escobar, facilitó la importación del repertorio teatral del West End londinense entre 1946 y 1950 (García Ruiz, 2007b: 96-100), fomentando la presencia de piezas de autores británicos en los escenarios españoles.

${ }^{3}$ Se ha integrado en el catálogo la entrada correspondiente a la traducción al vasco de La otra orilla (Beste ertza), por tratarse de una producción presentada a censura en 1970.
} 
dramaturgo ha tenido en el ámbito editorial. En la quinta columna del Anexo I se ha procedido a registrar la existencia de publicaciones de textos escénicos representados, identificados en su mayoría en los archivos de censura. Se ha cotejado y completado dicha información con datos procedentes de la red de bibliotecas públicas del estado (BPE) y bibliotecas universitarias (REBIUN), así como de la agencia del ISBN español; donde se han identificado 49 publicaciones a nombre de López Rubio, de las que sólo siete se refieren a traducciones.

Si tomamos como referencia antologías de teatro español contemporáneo (López Rubio, 1969) o la emblemática Colección Teatro, "una de las colecciones teatrales más prolíficas" del siglo pasado (Puebla 2012: 16), en la que se publicaron 922 textos correspondientes a versiones escénicas del periodo 1951-1976 (Puebla 2012: 16), comprobamos que López Rubio figura con un número de publicaciones igual al de Buero Vallejo. Del total de 27 entradas registradas a su nombre, 16 corresponden a obras originales y 11 a traducciones (Puebla 2012: 35).

La dispar presencia del López Rubio dramaturgo-traductor en el ámbito escénico y el puramente editorial, nos hace pensar que, aunque su obra traducida llegó a los escenarios de forma constante y en cantidad apreciable, no obstante, muchos de sus textos quedaron archivados y por tanto inéditos e inaccesibles, excepto en los archivos de censura o en el propio fondo documental privado (CDAEA).

Se podría decir que la trayectoria de José López Rubio como autor y como traductor refleja de una manera bastante aproximada el acontecer teatral español. El grueso del teatro en la escena española se programaba siguiendo las tendencias internacionales, tratando de importar obras, autores y temas que hubieran tenido éxito en otros paises. Es claro el influjo del teatro representado en Broadway, o en Londres, o en París; también lo es la influencia de la gran pantalla a la que se adaptaban textos teatrales y de la que se derivaba un argumento inequivoco: la posible rentabilidad económica en el ámbito español de productos extranjeros de éxito probado. Y López Rubio era el mediador ideal: experto en manejar textos teatrales y guiones filmicos, con un dominio contrastado de idiomas y un conocimiento directo del medio teatral y cinematográfico (García Ruiz, 2007a: 83-89).

No es de extrañar, pues, que llegaran a sus manos proyectos complejos como la traducción de musicales (Al sur del Pacífico o El hombre de la Mancha) o que apareciera su nombre al frente de versiones de obras como La muerte de un viajante (Espejo, 2002). Su producción original llegó de forma regular a los escenarios españoles, y sus piezas de mayor éxito se vieron en la pequeña pantalla o, incluso, se adaptaron al cine.

López Rubio, además de hombre de teatro, conocido sobre todo por sus comedias, fue un profesional del cine y la televisión. Un intento de 
recopilación de su obra en los medios audiovisuales nos lleva inevitablemente a la producción previa a la guerra civil, en la Metro y la Fox (Armero 1995, Torrijos 1999). Pero, además, ha quedado constancia de su intervención como guionista en España después de $1939^{4}$. En la historia reciente de medios audiovisuales como el televisivo, López Rubio ha dejado un legado importante con series como Al Filo de lo imposible (Rodríguez Fischer, 2008) o Mujeres en la historia (Holt 1980: 119-128). Un puñado de sus textos teatrales, tanto originales como traducidos, fueron producidos y emitidos por RTVE-Radio Televisión Española, en espacios como Estudio 1, y aparecen catalogados en fuentes como el Internet Movie Database (IMDB) o la base de datos de películas calificadas del Ministerio de Cultura (MCU) que ofrecen, a fecha de hoy, datos sobre su labor como adaptador, guionista, director e incluso actor.

En este estado de cosas quizá convenga añadir una secuencia más al metraje documental del que hablábamos al principio y que hemos intentado recomponer a base de recortes e instantáneas. De todos los expedientes de censura que nos han servido para reconstruir el catálogo de obras firmadas por López Rubio, procederemos a presentar el correspondiente a la producción musical El hombre de La Mancha. Dicha producción se utilizó desde el propio régimen franquista, en pleno proceso de "apertura" política en los años sesenta del siglo pasado (Muñoz Cáliz 2005: 133-149), para fomentar una imagen positiva de España en la sociedad occidental.

\section{El hombre de La Mancha: producción teatral para un periodo de apertura}

El expediente 231/66 correspondiente a la tramitación de permiso para representar el musical El hombre de la Mancha (Wasserman, 1999), en traducción de José López Rubio, podría considerarse un caso prototípico de autorización apoyada por las autoridades encargadas de gestionar el teatro en un periodo de apertura. Analizando la documentación contenida en el expediente vemos cómo el productor (Justo Alonso) y director del espectáculo (José Osuna), junto con el propio director general de Cinematografía y Teatro (José María García Escudero) y el ministro de Información y Turismo (Manuel Fraga), colaboraron para fomentar, con el estreno de este musical, la imagen de un teatro español, moderno, vivo y, sobre todo, homologable a nivel internacional. Esta actitud está en sintonía con lo que se denominó "liberalización de fachada", en la década de 1960, y que posibilitó la presencia de dramaturgos extranjeros (Brecht, Sartre o Weiss) en detrimento -según Alfonso Sastre- de los nacionales (Muñoz Cáliz, 2005: 143).

Si consultamos la documentación custodiada en el AGA para el

\footnotetext{
${ }^{4}$ La base de datos de películas calificadas del Ministerio de Cultura, registra 24 entradas bajo el nombre de José López Rubio, guionista.
} 
expediente 231/66, correspondiente a El Hombre de la Mancha, (ver el Anexo 2), lo primero que llama la atención es la existencia de contactos previos a la solicitud formal de permiso de representación (18/08/1966). Parece que el objeto de dichos contactos, recogidos en la carta dirigida al Director General, José María García Escudero, firmada por José Osuna, en la que se menciona "nuestra última entrevista", era doble: por un lado, se pretendía obtener una especie de autorización previa, de modo que el riesgo empresarial relacionado con el montaje de un espectáculo musical de gran calado fuera mínimo; y por otro, conseguir que las autoridades fueran propicias a la concesión de una subvención ("solicitud de ayuda económica"), que garantizara la viabilidad y éxito del proyecto con el argumento de "la casi obligación moral que tenemos en España de representar esta obra".

En la documentación que consta en el expediente, encontramos la mencionada carta y, en la misma fecha (21/5/1966), una instancia suscrita por José Osuna y Justo Alonso, en nombre de la producción teatral, dirigida al ministro, insistiendo en que creen conveniente importar el gran éxito neoyorkino, cuyo protagonista es Cervantes, en "una misión casi de cultura hispánica". En consecuencia, solicitan que se les dote de los "medios económicos necesarios".

Dos meses más tarde (23/7/1966) el director general se dirige al ministro en relación con el "estreno de esta obra en Madrid, primera ciudad del mundo en la que se ofrece después del éxito en Nueva York". Le informa de que ha tenido acceso, con carácter previo a la presentación formal ante la censura, a "una versión muy literal"; estima que esta no ofrece reparos, excepto en lo tocante a unas escenas en que Cervantes aparece encarcelado por la Inquisición; añadiendo que el director del espectáculo, José Osuna, le ha asegurado que dichas escenas "serán total y absolutamente eliminadas".

El 18 de agosto se presenta la solicitud preceptiva que es tramitada sin dificultades, y con la recomendación por parte de uno de los censores de que "las efusiones de Aldonza con los criados" se vigilen en el visado de ensayo general. La autorización para mayores de 18 años, sin supresiones, se expide el 24 de agosto, con la inusual clasificación de "radiable"

En el expediente se archivan tres textos mecanografiados en español: la primera "versión muy literal" de López Rubio, el texto adaptado, que recoge las supresiones y modificaciones, y las canciones ("cantables") que se tramitan en último lugar. El cotejo de dichos textos con el original parece indicar que la primera versión sigue el original inglés, sin supresiones ni adiciones. En el segundo texto, "adaptado" siguiendo las

\footnotetext{
${ }^{5}$ El que una obra de teatro obtuviera la autorización para su retrasmisión radiofónica era excepcional pues por defecto se calificaba el grueso del teatro como 'no radiable'. En casos aislados, la clasificación 'radiable' nos indica que se estima que el texto es totalmente inocuo y claramente autorizable.
} 
indicaciones de las autoridades, se suprimen las referencias a la Inquisición, y se pueden apreciar adiciones y modificaciones que parecen haber sido propuestas por agentes externos al aparato censor.

El autor del libreto, Dale Wasserman, cuando asistió al estreno, el 30 de septiembre de 1966, en el Teatro de la Zarzuela de Madrid, se percató de que las primeras líneas de la novela de Cervantes habían sido integradas al comienzo de la obra, y de que el tema musical principal, "El Sueño Imposible", lo interpretaba Aldonza (Nati Mistral) en lugar de Don QuijoteCervantes (Luis Sagi-Vela). En su conversación con López Rubio, tras el estreno, le preguntó sobre estos cambios (Wasserman, 2003, 152-54), contestándole al parecer el traductor que el propio título del musical había llevado a adelantarse a las expectativas del público espectador español, evocando las primeras líneas de la famosa novela; y que Nati Mistral era "una estrella"6.

Si situáramos este caso en una escala que recogiera desde el teatro prohibido hasta el permitido, durante este mismo periodo, veriamos que la producción de El hombre de la Mancha no sólo fue autorizada sin problemas, sino que lo fue antes de presentar la solicitud formal, y recibió incluso apoyo económico. En el extremo contrario, la prohibición, inicial o definitiva, que impidió la representación, podríamos mencionar obras como La caza real del sol (3/69)de Peter Shaffer; o La esposa constante (189/44) de Somerset Maugham y Panorama desde el Puente de Arthur Miller (195/58). Tanto los casos de prohibición total como los de autorización sin ambages fueron poco frecuentes en el periodo. La mayoría de los expedientes de censura consultados y estudiados hasta la fecha, se refieren a producciones que tuvieron que salvar objeciones, más o menos importantes, antes de llegar a escena. Así, el polémico caso de ¿Quién teme a Virginia Woolf? (215/65), de Edward Albee, dirigida por Osuna; o La Baye (387/67) de Philippe Adrien, traducida por López Rubio, presentaban, en opinión de los censores, objeciones relacionadas con un lenguaje soez y una inmoralidad manifiesta, escollos que a pesar de todo resultaron negociables.

En la década de 1960, el entorno de la cultura teatral favorecía la confrontación de las fuerzas innovadoras con aquellas que se resistían al cambio, tanto dentro como fuera de la estructura del estado. La pugna se daba no sólo entre lo que se consideraba teatro de la derecha como de la izquierda (Monleón, 1971) sino entre el teatro escrito por autores españoles y el importado ${ }^{7}$. La importación de temas tabúes mediante la

\footnotetext{
${ }^{6}$ En la versión estrenada en Madrid el 19 de octubre de 1997 en el Teatro Lope de Vega, con adaptación de Nacho Artime e interpretación de Paloma San Basilio y José Sacristán, se mantienen estos cambios (Díaz Sande, 1998: 18). Wasserman también da cuenta de otras adaptaciones polémicas del texto para las representaciones en Praga (2003: 155-56) o en París, en versión de Jacques Brel (2003: 163-64), a finales de la década de 1960.

${ }^{7}$ López Rubio fue miembro del Comité Editorial de Primer Acto, revista dirigida por José Ángel Ezcurra y José Monleón, con quienes compartió tertulia en la sede de la revista Triunfo: 〈 http://primeracto.com/jose-angel-ezcurrà.
} 
traducción parece haber sido la norma en un periodo en que a los autores nacionales se les medía con una vara diferente y se controlaba la temática de producción original con más ahínco y celo censor que la de origen foráneo.

Hubo en la época franquista un teatro "más allá de Lorca" (Halsey \& Zatlin, 2011) y más allá de Buero o Sastre (O'Connor, 1969; Cramsie, 1984; García Obregón, 2006), al que se ha prestado una atención muy limitada, quizá por estimar que fue producido sin dificultad o confrontación aparente. Al igual que el componente traducido de la historia teatral española, cuyo estudio ha sido poco abordado, hay figuras como la de López Rubio que merecen una mayor atención en el ámbito académico.

Desde la perspectiva de la historia de la traducción de teatro en España, la figura del dramaturgo José López Rubio como mediador, no por discreta resulta menos indispensable. Su modestia y discreción encajan a la perfección con la función que los traductores de obra dramática tenían asignada: siempre en un segundo plano, intervenían en el texto por encargo, siguiendo instrucciones de empresarios, directores, censores y editores. Reescribian las piezas teatrales sin gozar de una posición de poder, hasta el punto de que otros agentes del mundo teatral más poderosos, desde directores hasta actores, llegaban a apropiarse de sus textos, incluso para utilizarlos en programas de mano, ediciones o adaptaciones televisivas.

Si bien es cierto que "there has been a tendency in the academic world to treat Spain's modern theater as a phenomenon occurring in extreme isolation and as an aspect of artistic creativity almost totally neutralized by censorship" (Holt, 1975: 9), y aunque es un hecho constatado que la censura dejó su huella en todo tipo de manifestación cultural, no lo es menos que la vida escénica en España, la escrita originalmente en español y la traducida, a pesar de la restricción censora, y en ocasiones precisamente por ella, fue rica, variada y diversa.

Este trabajo muestra la importancia que el teatro traducido tuvo en la evolución escénica española así como su incidencia en nuestro devenir cultural. De ahí la necesidad del estudio en profundidad de autores como el que nos ocupa, que ayudan a matizar la visión que se tiene del teatro español durante el periodo franquista y ponen en movimiento imágenes fijas que, vistas en secuencia, ofrecen una perspectiva más ajustada a la realidad del acontecer teatral cotidiano. 


\section{Bibliografía}

Álvaro, F. 1958. El Espectador y la crítica. El teatro en España en 1958. Valladolid: Edición del autor. [Volúmenes anuales 1958-1985.]

Armero, A. 1995. José López Rubio. Las versiones hispanas. In: A. Armero Una aventura americana, españoles en Hollywood. Madrid: Compañía Literaria, pp. 13-24.

Berenguer, A. \& Pérez M. 1998. Tendencias del teatro español durante la transición política (1975-1982). Madrid: Biblioteca Nueva.

Bonnín, I. 1998. El teatro español desde 1940 a 1980. Barcelona: Octaedro.

Cramsie, H. 1984. Teatro y censura en la España franquista: Sastre, Muñiz y Ruibal. New York: Peter Lang.

Díaz Sande, J. R. 1998. El hombre de la Mancha. Nada que envidiar a Hollywood. Reseña, 290: 18 [online] [consultado en enero de 2014]. Disponible en: 〈http://www.madridteatro.eu/teatr/teatro/teatro062.htm〉

Díez Borque, J.M dir. 1982. Historia del teatro en España, I. Siglo XVI. Siglo XVII. Madrid: Taurus.

Díez Borque, J.M dir. 1988. Historia del teatro en España, II. Siglo XVIII. Siglo XIX. Madrid: Taurus.

Espejo, R. 2002. Death of a Salesman, de Arthur Miller, en España durante los años 50. Atlantis 24(2): 85-107.

Ferreras, J.I. 1988. El teatro en el siglo XX (desde 1939). Madrid: Taurus.

García Lorenzo, L. 1981. El teatro español después de Franco, 1976-1980, Segismundo: revista hispánica de teatro, 14(27-32): 271-85.

García Obregón, O. 2006. El (im)posibilismo teatral: Buero y Sastre frente a la censura. Serie: Diálogos con la censura, vol. 1. Miami: CERA.

García Ruíz, V. 2007a. Tres humoristas en busca del teatro: Mihura, López Rubio y Neville hacia 1950. ALE, Anales de Literatura Española, 19: 81100.

García Ruíz, V. 2007b. El baile de Edgar Neville: un tiempo dormido. In: J. A. Ríos Carratalá, ed. Universo Neville. Málaga: Instituto Municipal del Libro, 87-115.

García Ruíz, V. 2008. Comedia y comedia del humor en la posguerra española: dos humoristas y dos comediógrafos. Revista Iberoamericana, 19-2: 241-278.

Halsey, M. \& Zatlin, Ph. 2011. Beyond Lorca. Contemporary Theatre Review. $7(2): 61-80$.

Holt, M. P. 1964. The Theatre of José Lopez Rubio. Tesis doctoral sin publicar, University of Illinois.

Holt, M. P. 1975. The contemporary Spanish Theatre (1949-1972). Boston: Twayne.

Holt, M. P. 1980. José López Rubio. Boston: Twayne.

Huerta Calvo, J. ed. 2003. Historia del teatro español. Madrid: Gredos.

Isabel Estrada, M. A. 2001. George Bernard Shaw y John Osborne: recepción 
y recreación de su teatro en España durante el franquismo. Tesis doctoral, Universidad Complutense, Madrid.

López Rubio, J. 1969. Teatro Selecto. Prólogo de Alfredo Marquerie. Madrid: Escelicer.

Merino Álvarez, R. 1994. Traducción, tradición y manipulación. Teatro inglés en España 1950-90. León: Universidad de León \& Universidad del País Vasco. Disponible en: 〈http://hdl.handle.net/10810/15988〉

Merino Álvarez, R. 2008. La homosexualidad censurada: estudio sobre corpus de teatro TRACEti (desde 1960). In: R. Merino, ed. Traducción y censura en España (1939-1985). Estudios sobre corpus TRACE: cine, narrativa, teatro. Bilbao: Universidad del País Vasco/Universidad de León, pp. 243-286. Disponible en: 〈http://hdl.handle.net/10810/10169〉

Merino Álvarez, R. 2009. Building TRACE (translations censored) theatre corpus: some methodological questions on text selection. In: M. Muñoz, ed. Translation and Cultural Identity: Selected Essays on Translation and Cross-Cultural Communication, Newcastle: Cambridge Scholars Publishing. Disponible en: $\langle$ http://hdl.handle.net/10810/17411 $\rangle$

Merino Álvarez, R. 2010. La historia de las traducciones de teatro inglés en España en el siglo XX: perspectiva desde el proyecto TRACE. In: $R$. Rabadán et. al., eds. Lengua, traducción, recepción. En honor de Julio César Santoyo/Language, translation, reception. To honor Julio César Santoyo. León: Universidad de León, pp. 357-384. Disponible en: $\langle$ http://hdl.handle.net/10810/15986〉

Merino Álvarez, R. 2011. Diez años de investigación sobre teatro traducido en España: el proyecto TRACE y los archivos de censura, Represura. Revista de Historia Contemporánea española en torno a la represión y la censura aplicadas al libro, 7 [online] Disponible en: 〈http://hdl.handle.net/10810/10145〉

Merino Álvarez, R. 2012. A historical approach to Spanish theatre translations from censorship archives. In: García-Izquierdo, I. \& E. Monzó, eds. Iberian Studies on Translation and Interpreting. Oxford: Peter Lang, pp. 123-140.

Miguel Martínez, E. 2000. Teatro español 1980-2000: catálogo visitado. Salamanca: Ediciones de la Universidad de Salamanca.

Monleón, J. 1971. Treinta años de teatro de la derecha. Barcelona: Tusquets.

Muñoz Cáliz, B. 2005. El teatro crítico español durante el franquismo visto por sus censores. Madrid: Fundación Universitaria Española.

Muñoz Cáliz, B. 2012. Fuentes y recursos para el estudio del teatro español. Madrid: Centro de Documentación Teatral.

O'Connor, P. 1969. Censorship in Contemporary Spanish Theater and Antonio Buero Vallejo. Hispania 52: 282-88.

Oliva, C. 2002. Teatro español del siglo XX. Madrid: Editorial: Síntesis.

Pérez López de Heredia, M. 2005. Inventario de las traducciones censuradas de teatro norteamericano en la España de Franco (19391963). In: R. Merino, J. M. Santamaría \& E. Pajares, eds. Trasvases 
culturales: literatura, cine y traducción, 4. Bilbao: Universidad del País Vasco, pp. 97-112.

Pérez, M. 1998. Las críticas teatrales como fuentes de la historia del teatro. In: El teatro de la Transición Política (1975-1982). Recepción, crítica y edición. Kassel: Reinchenberger, pp. XIII-XXIV.

Pérez López de Heredia, M. 2005. Inventario de las traducciones censuradas de teatro norteamericano en la España de Franco (1939-1963). En: R. Merino, J. M. Santamaría y E. Pajares, eds. Trasvases culturales: literatura, cine y traducción, 4. Bilbao: Universidad del País Vasco, pp. 97-112.

Puebla, L. 2012. Colección Teatro de Editorial Escelicer. Madrid: Centro Documentación Teatral.

Rodríguez Fischer, A. 2008. El otro López Rubio. Revista de Libros, 143(noviembre).

Rogers, E. S. 1980. Casona and López Rubio: Theatre as real life. Rocky Mountain Review of Language and Literature, 34(2): 135-149.

Romera Castillo, J. 1997. Edgar Neville y el cine. A distancia. UNED. Otoño (IX-XIII): 223-243.

Romera Castillo, J. 2003. Perfiles autobiográficos de la otra generación del 27 (la del humor). In: J. Romera Castillo, ed. Teatro y memoria en la segunda mitad del S. XX. Madrid: Visor, pp. 221-243.

Ruiz Ramón, F. 1989. Historia del teatro español. Siglo XX. Madrid: Cátedra.

Santoyo Mediavilla, J. C. 1983. La Cultura Traducida. Lección inaugural del curso académico 1983-84. León: Universidad de León.

Schiding, E. 2007. Theatrical Renovation and Social Criticism in the PostWar Plays of Enrique Jardiel Poncela. PhD thesis, Baylor University.

Torrijos, J. M. ed. 2003. José López Rubio. La otra generación del 27. Discurso y cartas. Madrid: Centro de documentación teatral.

Toury, G. 2004. Los estudios descriptivos de traducción, y más allá. Metodología de la investigación en estudios de traducción. Traducción, introducción y notas R. Rabadán \& R. Merino. Madrid: Cátedra.

Utrera Macías, R. 1987. José López Rubio, el académico que vivió en Hollywood. In: Literatura cinematográfica y cinematografía literaria. Sevilla: Alfar, pp. 83-86.

Wasserman, D. 1999. Don Quixote as theatre. Cervantes: Bulletin of the Cervantes Society of America, 19(1): 125-130.

Wasserman, D. 2003. The imposible musical. The 'Man of La Mancha' Story. New York: Applause. Theatre and cinema books. 


\section{Fuentes en internet}

AGA. Archivo General de la Administración [online] [consultado enero de 2014]. Disponible en: 〈http://www.mcu.es/archivos/MC/AGA/index.html〉

BPE. Bibliotecas Públicas del Estado [online] [consultado enero de 2014]. Disponible en: 〈http://www.mcu.es/bibliotecas/MC/CBPE/〉

CDAEA. Centro de Documentación de las Artes Escénicas de Andalucía [online] [consultado enero de 2014]. Disponible en: 〈http://www.juntadeandalucia.es/culturaydeporte/cdaea/〉

CDT. Centro de Documentación Teatral [online] [consultado enero de 2014]. Disponible en: 〈teatro.es〉

IMDB. Internet Movie Database [online] [consultado enero de 2014]. Disponible en: http://www.imdb.com

ISBN. Bases de datos [online] [consultado enero de 2014]. Disponible en: 〈http://www.mcu.es/libro/CE/AgenISBN.html〉

MCU. Base de datos de películas calificadas. Ministerio de Cultura [online] [consultado enero de 2014]. Disponible en: 〈http://www.mcu.es/bbddpeliculas〉

REBIUN. Red de Bibliotecas Universitarias [online] [consultado enero de 2014]. Disponible en: 〈http://rebiun.crue.org〉

Retratos. 2006. Canal Sur Televisión [online] [consultado enero de 2014]. Disponible en:

http://blogs.canalsur.es/documentacionyarchivo/tag/retratos-canalsur-tv/ 〈http://www.youtube.com/watch?v=0a5zO4tyfSy〉 


\section{ANEXO 1. Catálogo de textos escénicos firmados por José López Rubio}

\begin{tabular}{|c|c|c|c|c|c|}
\hline Titulo $^{8}$ & Autor & $\begin{array}{l}\text { Expediente } \\
\text { AGA }\end{array}$ & Estreno & Publicación & TV \\
\hline El pasado de la Señora Cheyney & Frederick L. & $469 / 45$ & 1945 & & \\
\hline El tiempo dormido & Levy, Ben W. & & 1947 & & \\
\hline El burgués gentilhombre & Moliére & $253 / 48$ & 1948 & & \\
\hline ALBERTO & LÓPEZ RUBIO, JOSÉ & $157 / 49$ & 1949 & СТ 30, 1952 & 1964 \\
\hline CELOS DEL AIRE & LÓPEZ RUBIO, JOSÉ & $\begin{array}{l}19 / 50 \\
329 / 82\end{array}$ & 1950 & CT 2, 1951 & $\begin{array}{l}1971 \\
1977 \\
1989\end{array}$ \\
\hline Tovarich & Deval, J. & $167 / 50$ & 1950 & CT4, 1951 & 1970 \\
\hline ESTOY PENSANDO EN TI & LÓPEZ RUBIO, JOSÉ & $209 / 50$ & 1950 & CT100, 1954 & \\
\hline Belinda & Harris, E. & $500 / 50$ & 1950 & & \\
\hline Sor Buenaventura & Hastings, Ch. & $531 / 50$ & 1950 & & \\
\hline UNA MADEJA DE LANA AZUL CELESTE & LÓPEZ RUBIO, JOSÉ & $22 / 51$ & 1951 & CT14, 1952 & 1964 \\
\hline VEINTE Y CUARENTA & LÓPEZ RUBIO, JOSÉ & $35 / 51$ & 1951 & CT30, 1952 & \\
\hline DE LA NOCHE A LA MAÑANA & $\begin{array}{l}\text { UGARTE PAGÉS, E. } \\
\text { LÓPEZ RUBIO, JOSÉ }\end{array}$ & $110 / 51$ & 1951 & $\begin{array}{l}\text { CT190, } 1958 \\
\text { [+LA CASA DE } \\
\text { NAIPES] }\end{array}$ & 1974 \\
\hline CENA DE NAVIDAD & LÓPEZ RUBIO, JOSÉ & $383 / 51$ & 1951 & CT8, 1951 & 1966 \\
\hline La esposa constante & $\begin{array}{l}\text { Somerset Maugham, } \\
\text { W. }\end{array}$ & $\begin{array}{l}189 / 44 \\
324 / 51\end{array}$ & 1952 & CT26, 1952 & \\
\hline PRIMERA AVENTURA & LÓPEZ RUBIO, JOSÉ & & 1952 & & \\
\hline La muerte de un viajante & Miller, A. & $\begin{array}{l}3 / 52 \\
311 / 84\end{array}$ & 1952 & $\begin{array}{l}\text { CT14, } 1952 \\
\text { [MK Ediciones, 1985] }\end{array}$ & \\
\hline Completamente honesta & Sturges, P. & $67 / 52$ & 1952 & & \\
\hline La plaza de Berkeley & Balderston, J. L. & $107 / 52$ & 1952 & CT27, 1952 & \\
\hline
\end{tabular}

${ }^{8}$ Título: las entradas en versalitas se refieren a obras originales, el resto se trata de traducciones y adaptaciones firmadas por López Rubio. Expediente AGA: número de expediente de censura consultado en el AGA-Archivo General de la Administración (número/año). Estreno: año de estreno. Publicación: CT, Colección Teatro,

Editorial Escelicer/Alfil. Se especifica número de la colección y año de publicación. TV: Fecha de emisión en televisión, RTVE, Radio Televisión Española. 


\begin{tabular}{|c|c|c|c|c|c|}
\hline De las doce a las tres & Vaszary, J. & $121 / 52$ & 1952 & & \\
\hline Sombra querida & Deval, J. & $220 / 52$ & 1952 & CT102, 1953 & \\
\hline La importancia de llamarse Ernesto & Wilde, $\mathrm{O}$ & $327 / 52$ & 1952 & СТ39, 1952 & 1963 \\
\hline EL REMEDIO EN LA MEMORIA & LÓPEZ RUBIO, JOSÉ & $414 / 52$ & 1952 & CT58, 1952 & \\
\hline La oveja blanca (de la familia) & $\begin{array}{l}\text { Garde Peach, L., } \\
\text { Du } \\
\text { Hay, I. }\end{array}$ & $424 / 52$ & 1952 & & \\
\hline Europa y el toro & Fodor, L. & $289 / 53$ & 1953 & & \\
\hline Crimen perfecto & Knott, F. & $\begin{array}{l}357 / 53 \\
461 / 81\end{array}$ & 1953 & CT138, 1956 & \\
\hline LA VENDA EN LOS OJOS & LÓPEZ RUBIO, JOSÉ & $64 / 54$ & 1954 & CT129, 1954 & $\begin{array}{l}1964 \\
1972\end{array}$ \\
\hline CUENTA NUEVA & LÓPEZ RUBIO, JOSÉ & $232 / 54$ & 1954 & & \\
\hline $\begin{array}{l}\text { LA OTRA ORILLA } \\
\text { [BESTE ERTZA] }\end{array}$ & LÓPEZ RUBIO, JOSE & $\begin{array}{l}331 / 54 \\
{[244 / 70]} \\
289 / 81\end{array}$ & $\begin{array}{l}1954 \\
{[1970]}\end{array}$ & CT119, 1955 & $\begin{array}{l}1965 \\
1972\end{array}$ \\
\hline Al Sur del Pacífico & $\begin{array}{l}\text { Rodgers, R., } \\
\text { Hammerstein, } \mathrm{O} \text {. }\end{array}$ & $5 / 55$ & 1955 & & \\
\hline EL CABALLERO DE BARAJAS & LÓPEZ RUBIO, JOSÉ & $241 / 55$ & 1955 & CT151, 1956 & \\
\hline Liliom & Molnar, F. & $256 / 55$ & 1955 & & \\
\hline LA NOVIA DEL ESPACIO & LÓPEZ RUBIO, JOSÉ & $52 / 56$ & 1956 & & \\
\hline Toda la verdad & Mockie, Ph. & $156 / 56$ & 1956 & & \\
\hline UN TRONO PARA CRISTY & LÓPEZ RÚBIO, JOSÉ & $226 / 56$ & 1956 & CT174, 1957 & \\
\hline Lecciones de amor & Pitigrilli & $301 / 56$ & 1956 & & \\
\hline Requiem para una mujer & Faulkner, W. & $35 / 57$ & 1957 & & \\
\hline Como buenos hermanos & Hellman, L. & $135 / 57$ & 1957 & & \\
\hline El bosque petrificado & Sherwood, R.E. & $202 / 57$ & 1957 & & \\
\hline Estrella de Sevilla & Lope de Vega & & 1957 & & \\
\hline Panorama desde el puente & Miller, A. & $195 / 58$ & 1958 & & \\
\hline LAS MANOS SON INOCENTES & LÓPEZ RUBIO, JOSÉ & $\begin{array}{l}209 / 58 \\
64 / 80\end{array}$ & $\begin{array}{l}1958 \\
1980\end{array}$ & CT272, 1960 & $\begin{array}{l}1966 \\
1978 \\
1989\end{array}$ \\
\hline CANTANDO EN PRIMAVERA & LÓPEZ RUBIO, JOSÉ & $111 / 59$ & 1959 & & \\
\hline PAN Y TOROS & LÓPEZ RUBIO, JOSÉ & 195/59 & 1959 & & \\
\hline
\end{tabular}




\begin{tabular}{|c|c|c|c|c|c|}
\hline & & $174 / 60$ & 1960 & & \\
\hline El camino de Roma & Sherwood, R.E. & $271 / 59$ & 1959 & & \\
\hline El avaro & Molière & $246 / 59$ & 1960 & CT 263, 1960 & \\
\hline Dos para un balancín & Gibson, W. & $8 / 60$ & 1960 & & \\
\hline $\begin{array}{l}\text { UN SEXTO SENTIDO O DIANA ESTÁ } \\
\text { COMUNICANDO }\end{array}$ & LÓPEZ RUBIO, JOSÉ & $107 / 60$ & 1960 & CT331, 1962 & \\
\hline El uno y el otro. Gog y Magog & $\begin{array}{l}\text { Mac Dougall,R., Allan, } \\
\text { T. }\end{array}$ & $32 / 61$ & 1961 & & \\
\hline Los dos Sebastiani & $\begin{array}{l}\text { Howard L., } \\
\text { Crousse, R. }\end{array}$ & $111 / 61$ & 1961 & & \\
\hline El milagro de Ana Sullivan & Gibson, W. & $111 / 61$ & 1961 & & 1978 \\
\hline Esta noche tampoco & López Rubio, Jose & $221 / 61$ & 1961 & CT461, 1965 & 1970 \\
\hline El cardenal de España & Montherlant, $\mathrm{H}$. & $297 / 60$ & 1962 & & 1965 \\
\hline Juana de Lorena & Maxwell, A. & $290 / 62$ & 1962 & & \\
\hline Luz de gas & Hamilton, P. & $61 / 64$ & 1964 & & \\
\hline Un domingo en Nueva York & Krasna, N. & $36 / 63$ & 1964 & CT466, 1965 & \\
\hline El sucesor & Raffalt, R. & $61 / 64$ & 1964 & & \\
\hline NUNCA ES TARDE & LÓPEZ RUBIO, JOSÉ & $180 / 64$ & 1964 & CT464, 1965 & 1968 \\
\hline Tartufo & Molière & $106 / 65$ & 1965 & & \\
\hline Los huevos del avestruz & Roussin, A. & $132 / 65$ & 1965 & & \\
\hline Ese animal extraño & Arout, G. & $30 / 66$ & 1966 & & \\
\hline El hombre de la mancha & Wasserman, D. & $231 / 66$ & 1966 & & \\
\hline LA PUERTA DEL ÁNGEL & LÓPEZ RUBIO, JOSÉ & $331 / 66$ & 1966 & & 1986 \\
\hline Sonrisas y lágrimas & Lindsay, H., Crouse, R. & $284 / 68$ & 1968 & & \\
\hline La Baiiiiia & Adrien, $\mathrm{Ph}$. & $386 / 67$ & 1969 & CT599, 1969 & \\
\hline Adriano VII & Luke, P. & $204 / 69$ & 1969 & & \\
\hline VENENO ACTIVO & LÓPEZ RUBIO, JOSÉ & $432 / 71$ & 1971 & & \\
\hline EL CORAZÓN EN LA MANO & LÓPEZ RUBIO, JOSÉ & $170 / 72$ & 1972 & CT795, 1972 & \\
\hline EL ÚLTIMO HILO & LÓPEZ RUBIO, JOSÉ & & 1974 & & \\
\hline Harold y Maude & Higgins, C. & $459 / 75$ & 1976 & & \\
\hline
\end{tabular}




\section{ANEXO 2. Expediente AGA, 231/66. El hombre de la Mancha:}

21 de mayo de 1966. Carta de José Osuna dirigida el Director General de Cinematografía y Teatro, José María García Escudero.

Mi distinguido amigo: De acuerdo con nuestra última entrevista me es muy grato adjuntarle un dossier crítico sobre "El hombre de la Mancha" asi como cuanta documentación he podido reunir sobre la producción y una solicitud de ayuda económica que le ruego haga llegar al Excelentísimo Sr. Ministro. En un reciente viaje a Nueva York he podido presenciar personalmente como la obra interesa y conmueve a públicos de condición social y nivel intelectual muy distintos. Después de presenciar el espectáculo he quedado asombrado del amor, la dedicación y la inteligencia con que los autores americanos han tratado este tema tan español, respetando, e incluso ensalzando, de una manera sorprendente el espíritu de $D$. Quijote.

He vuelto de mi viaje convencido de la casi obligación moral que tenemos en España de representar esta obra, dejando aparte sus calidades, aunque solo fuera por solidaridad con un intento de tan magníficos resultados. Le agradezco muy sinceramente el interés con que hasta el momento ha acogido nuestro proyecto y le ruego encarecidamente nos preste su apoyo para el mejor logro de la producción española.

21 de mayo de 1966. Instancia dirigida al Excmo. Sr. Ministro de Información y Turismo.

Los abajo firmantes, Justo Alonso Osorio y José Osuna Lameyer, en nombre de la producción teatral "El hombre de la Mancha (título provisional) a V.E. con el debido respecto. Exponen: que tienen la intención de montar, en su versión española, la comedia musical americana "Man of the Mancha", cuyo protagonista es Cervantes y su argumento Don Quijote de La Mancha.... Se representa actualmente en Nueva York y constituye el gran éxito de la temporada, interesando a todo el público americano por una figura tan española y universal como Don Quijote y divulgando en una misión casi de cultura hispánica la personalidad de su inmortal autor Miguel de Cervantes... Para su producción en España se piensa en un elenco de primerísimo rango interpretativo, hasta el punto de que se han iniciado ya gestiones con el actor José Ferrer, que actualmente tomará el papel protagonista en la producción americana...También se piensa en los mejores elementos de tipo técnico y escenográfico, por lo que el proyecto resultará de elevado coste y muy difícil amortización para una empresa privada...

Por todo lo que se ha expuesto suplican sea facilitada su programación en el Teatro de la Zarzuela y dotada la empresa con los medios económicos necesarios para el mejor resultado del empeño.

23 de julio 1966. Carta del Director General de Cinematografía y Teatro al Excmo. Sr. Ministro de Información y Turismo

"Para el próximo otoño... se proyecta el estreno de la comedia musical "El hombre de la Mancha", que dirigirá José Osuna y en la que intervendrán como principales intérpretes Nati Mistral y Luis Sagi Vela... La obra... es uno de los acontecimientos teatrales más importantes de Norteamérica, donde lleva dos años ininterrumpidos de programación. He conocido una versión muy literal de la misma que se me ha entregado con carácter previo a su presentación formal ante la censura. Su autorización no ofrece reparos, excepto unas escenas en que se presenta a Cervantes encarcelado por la Inquisición... con carácter inmediato he comunicado a José Osuna la ineludible necesidad de superar esta objeción por lo inexacto y absurdo de tales escenas, y los graves reparos de todo orden que de ello podrían derivarse, y de los cuales tenemos antecedentes bien recientes y directos en la película "EL Greco".... José Osuna me ha hecho saber que esas escenas serán total y absolutamente eliminadas, exponiéndome, asimismo, su total coincidencia con nuestras apreciaciones, a las que no oponen, tampoco, reparo alguno los propios autores de la obra... Te seguiremos informando de cualquier incidencia, o circunstancia de interés, relacionada con el estreno de esta obra en Madrid, primera ciudad del mundo en la que se ofrece, después de su éxito en Nueva York, que aún continua. 
18 agosto 1966. Solicitud de permiso de representación.

Instancia firmada por Justo Alonso. Título: El hombre de la Mancha. Comedia musical. Autores: Dale Wasserman, Mitch Leight y Joe Darion.

Nacionalidad: norteamericana. Representante en España: Andrés Kramer. Traductor: José López Rubio. Cuadro artístico: Nati Mistral, Luis Sagi

Vela, José Franco. Fecha estreno: septiembre 1966. Teatro de la Zarzuela. Director: José Osuna. Decorador: Emilio Burgos. Músico: Maestro Moreno

Torroba.

23 agosto 1966. Certificado de autorización, firmado por el Secretario de la Junta de Censura Teatral. Se adjuntan informes de los vocales de Sr.

Aúz, Sr. Baquero, Sr. M. Ruiz, todos favorables.

["Las efusiones de Aldonza con los criados aconsejan el visado" (M. Ruiz)].

24 agosto 1966. Autorización. Guía de censura 1. Sr. Director de la Compañía de Nati Mistral. Autorizada para mayores de 18 años, sin supresiones. Radiable.

20 septiembre 1966. Solicitud de autorización de los "Cantables".

27 septiembre 1966. Autorización para mayores de 18, sin supresiones.

30 Septiembre 1966. Estreno. 


\begin{abstract}
[EN] Spanish theatre professionals were responsible for the integration of foreign theatre in Spanish stages in Francoist Spain. The role of theatre translators, or of Spanish playwrights-translators, has been seldom tackled, and the hundreds of versions of American or British plays are yet to be fully studied. This paper focuses on Spanish author José López Rubio, whose production, both originally written in Spanish and translated, has been thoroughly catalogued, using censorship archives as the main source of documentation. While compiling the catalogue it became clear that the number of translations signed by López Rubio is higher than that of original plays. This catalogue is analyzed and a specific case study is presented: the Broadway musical Man of La Mancha. This production saw its second world premiere in Madrid, with the aid of the authorities in charge of the Theatre and Cinema General Directorate, in the Ministry for Information and Tourism, who favoured a positive image of the regime abroad.

[ES] La integración del teatro extranjero en la escena española durante el franquismo tuvo como protagonistas a productores y directores teatrales, junto a traductores y otros profesionales del medio. De todos ellos las figuras más ignoradas han sido los traductores, y por tanto aquellos dramaturgos españoles que firmaron cientos de versiones traducidas de teatro estadounidense $o$ británico. Este artículo se centra en la figura del dramaturgo José López Rubio, cuya producción original y traducida se ha catalogado exhaustivamente, recurriendo a los archivos de censura como principal fuente documental. Al realizar dicha catalogación se ha constatado que el número de traducciones es significativamente mayor que el de obras originales. Se analiza dicho catálogo y se presenta un estudio de caso, la producción del musical El hombre de la Mancha. Esta producción importada desde Broadway tuvo su segundo estreno mundial en Madrid, gracias a la intervención de los responsables de la Dirección General de Cinematografía y Teatro del Ministerio de Información y Turismo que pretendian fomentar una imagen positiva del régimen en el exterior.
\end{abstract}

Keywords: translation, theatre, censorship, Francoism, López-Rubio Palabas Clave: traducción, teatro, censura, franquismo, López-Rubio 


\section{Nota sobre la autora}

Raquel Merino Álvarez (http://orcid.org/0000-0002-3772-0461) es catedrática de Traducción en la Universidad del País Vasco, donde imparte cursos de traducción inglésespañol. Entre sus líneas de investigación están la historia de las traducciones de teatro en España (siglo $X X$, con especial referencia al periodo franquista). Ha dirigido el proyecto TRACE (Traducción y censura) y actualmente dirige el grupo de investigación TRALIMA (Traducción, Literatura y Medios Audiovisuales), distinguido por el Gobierno Vasco como Grupo de Investigación Consolidado. 